號拾第卷入拾式第誌雑學類人

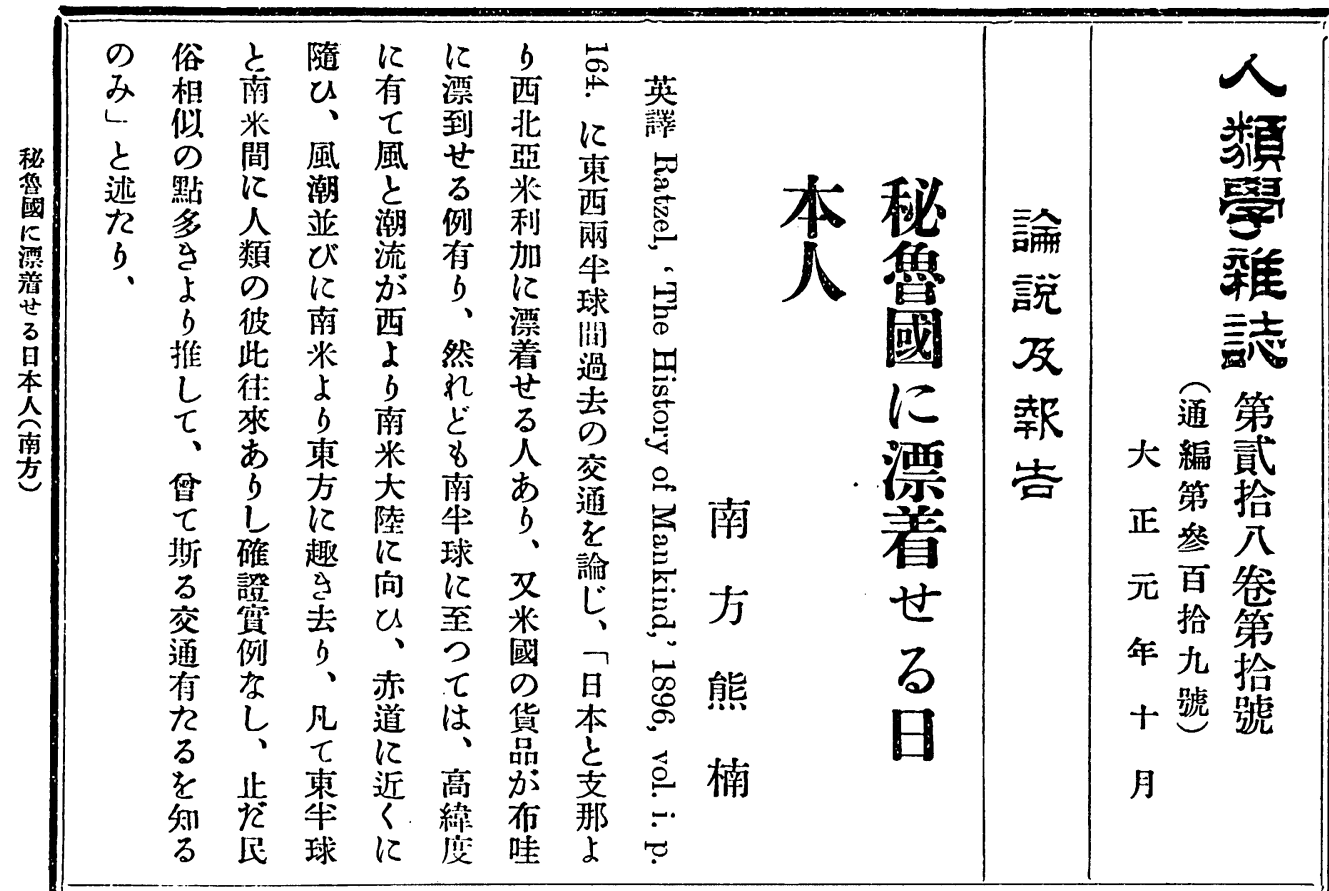

原 の

朋文絕今とグて移球海に移用主三第未

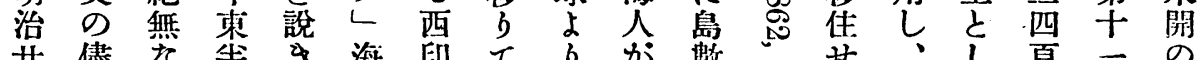

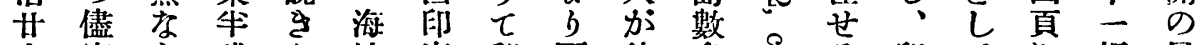

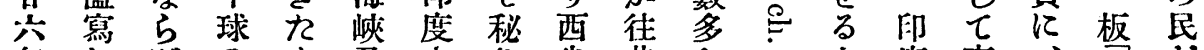

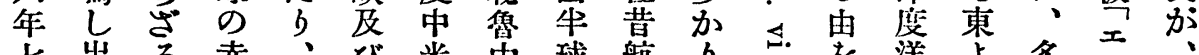

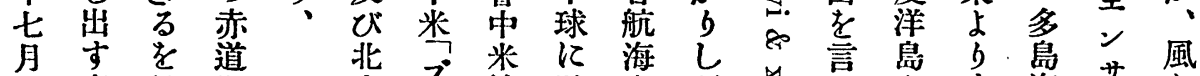

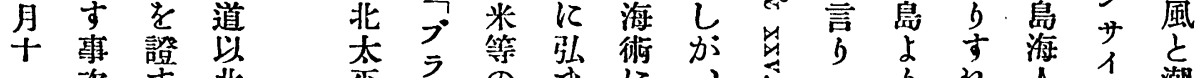

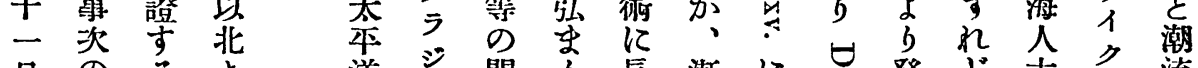

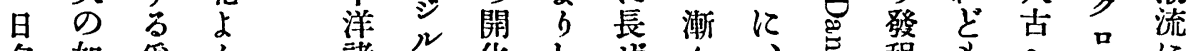
夕、如篇 3 諸管华 $L$ せ

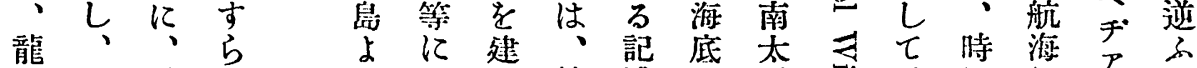

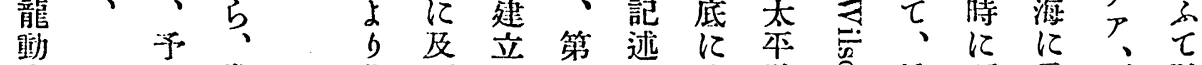

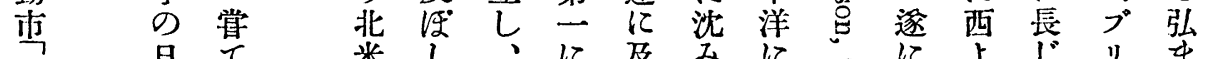

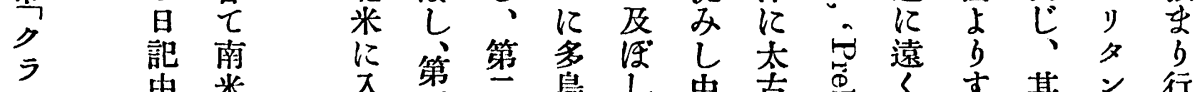
琴

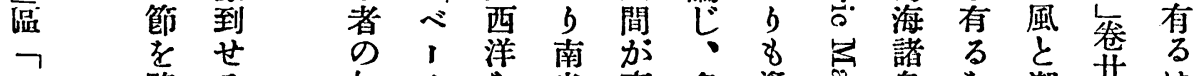

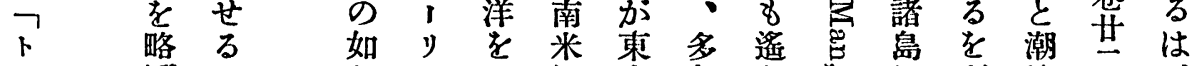

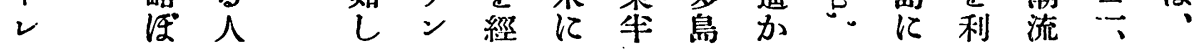


此相多其し 氏 印の再庭理二見藝とで皇

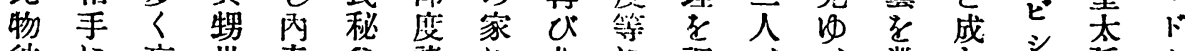
彼に忘册奇聲譇に北に調、、、業し

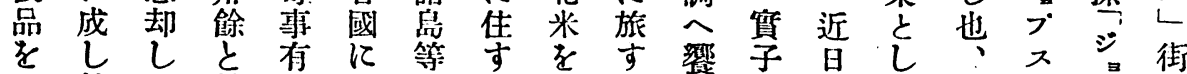

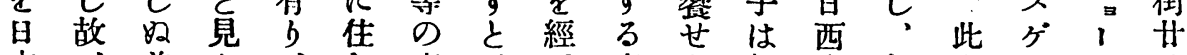

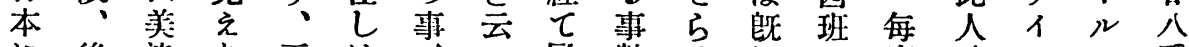

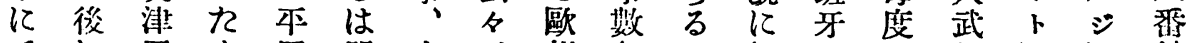
$\tau に$ 田 $b$ 田明大、州年、歸に水州しᄂ 馆 何は氐、某治抵旅各、主朝趣晶の街䚋竞

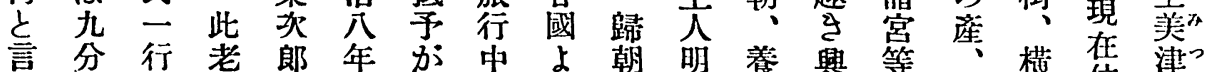

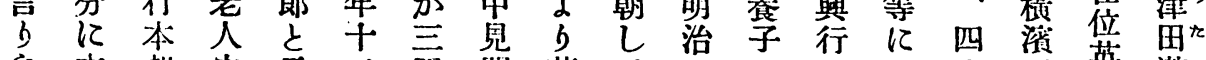

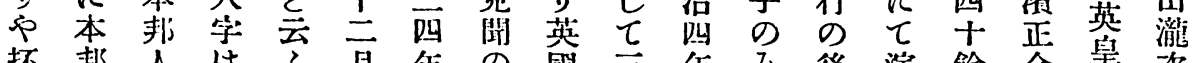
抔邦人は及月年の閏年み後演馀金皇次 問の十辈人に前種に年十留歸し葳銀の 郎

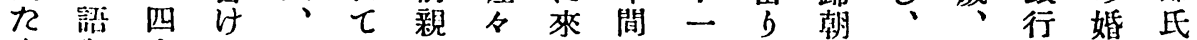

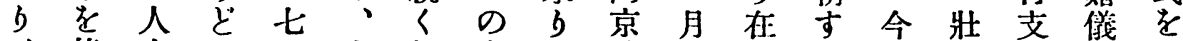
、能有的士六見奇、濱本与令は快店行訪

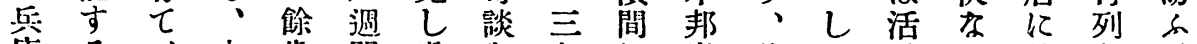

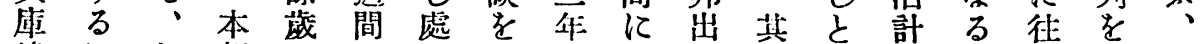

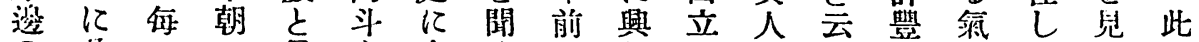

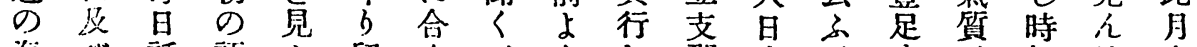

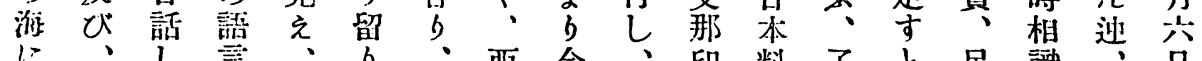
に、し言、 $b$ 西令、印料子と足倳、日

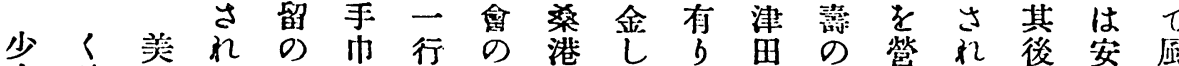

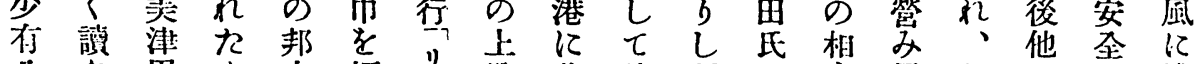

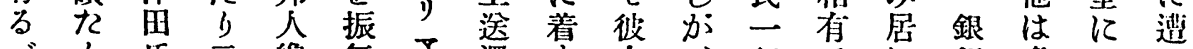

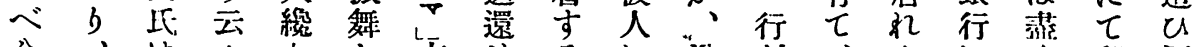

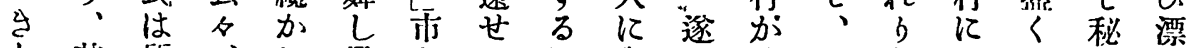

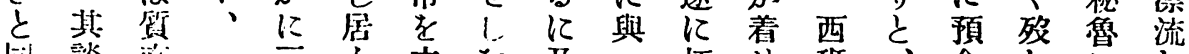

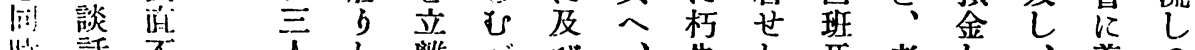

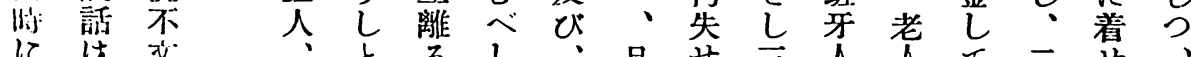

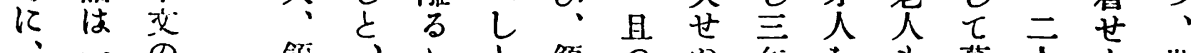

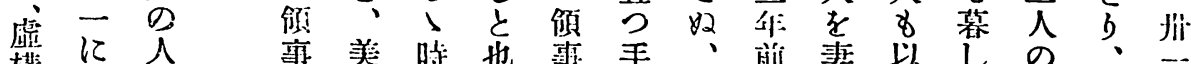

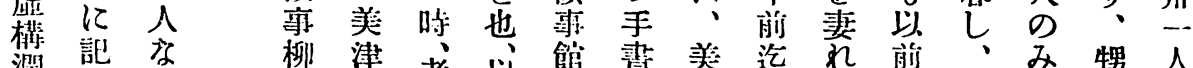

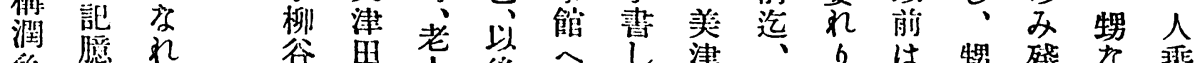

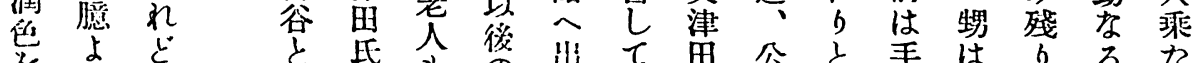
名

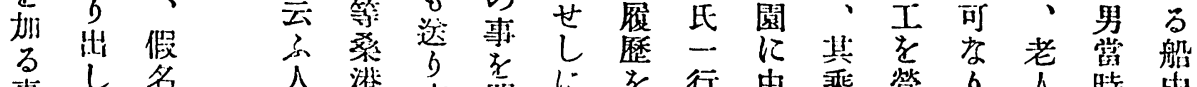

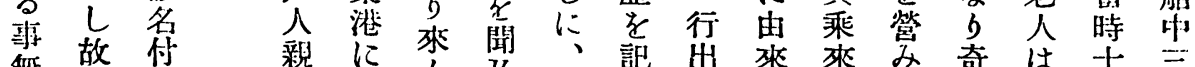

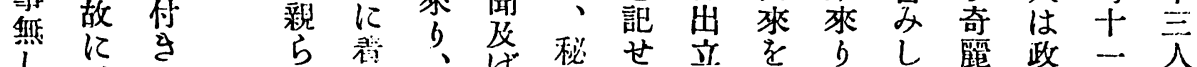

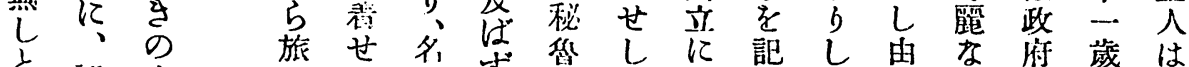

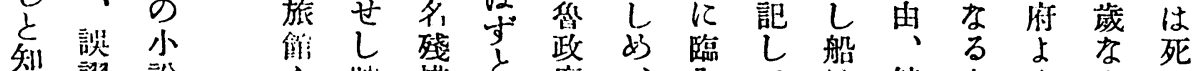

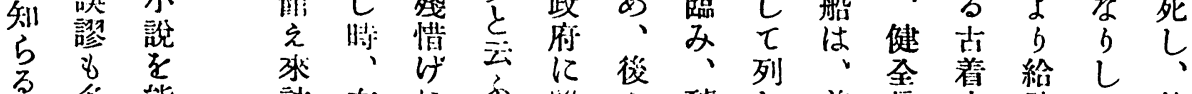

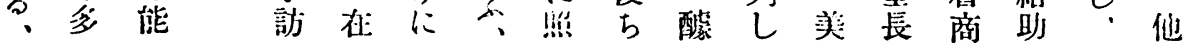


號拾第然入拾式第誌雜學類人

到後年て 治甚聞 ら龍人 じ

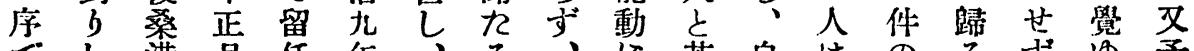

で港月任年、る、に英自はのるすかゆ予

に話に中せ十近安右三媂台筫美

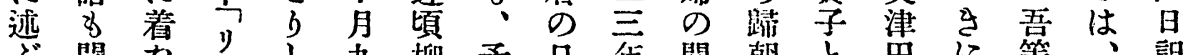

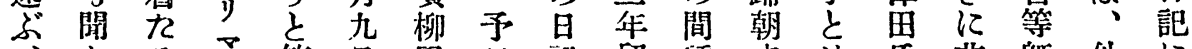

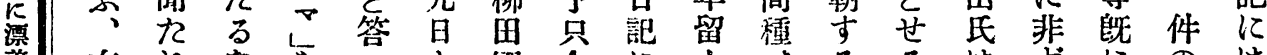

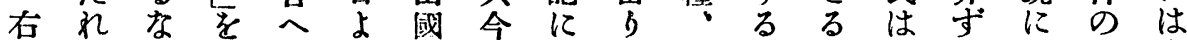

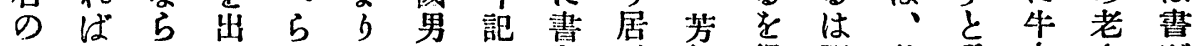

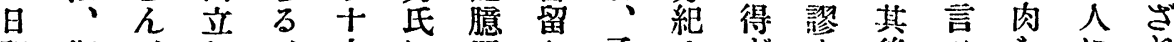

苯記 斯 、

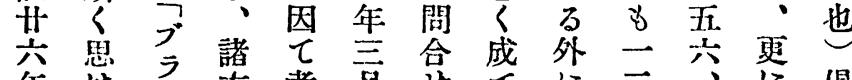

年は

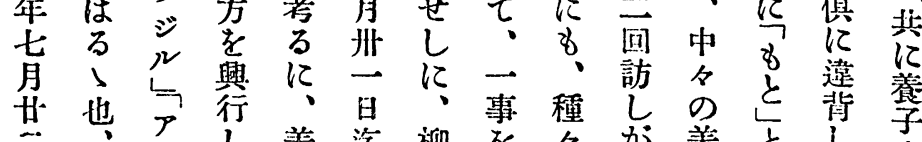

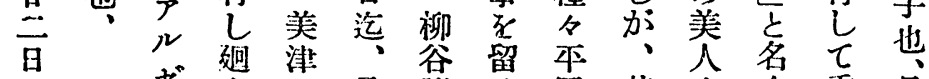

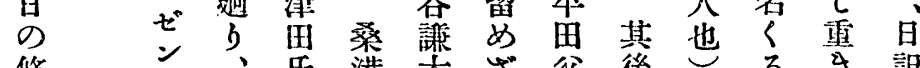

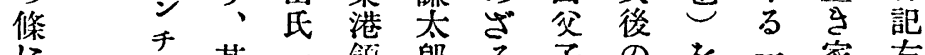

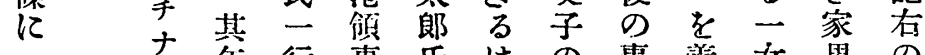

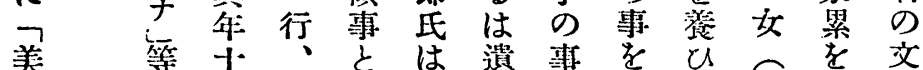

美等

津に月九明揻学知、邦に

\section{L 食}

食䅉

た碓

れ 膨北

ばめに

身し美

䆏に 津

礼、田

九最氐

り、初 の

日 它

本承

に况

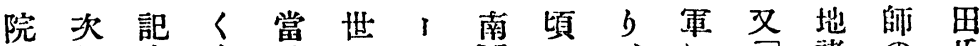

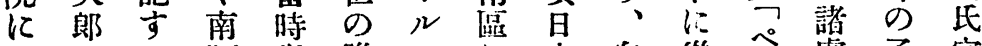

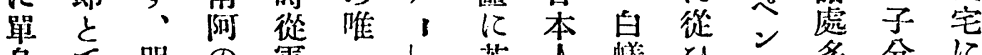

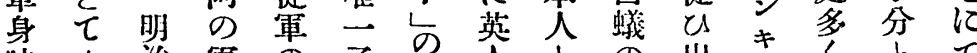

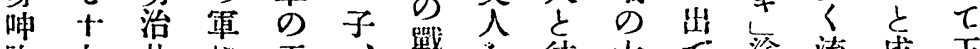

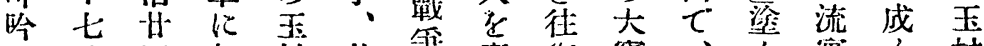

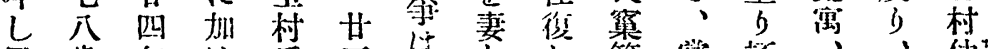

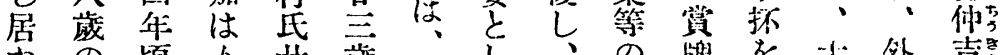
ての頃り 甘藏明し、の 牌老

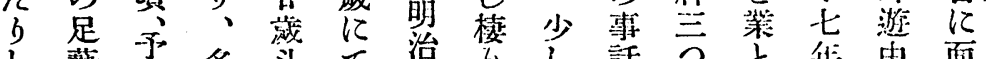

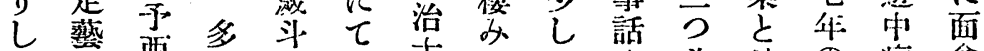

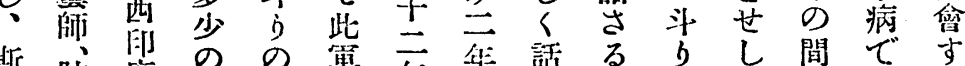

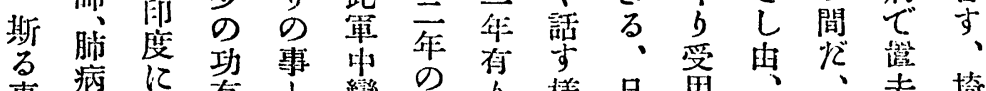

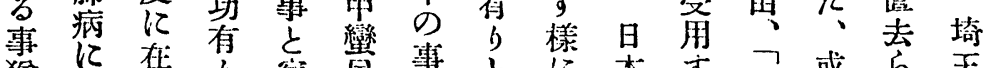

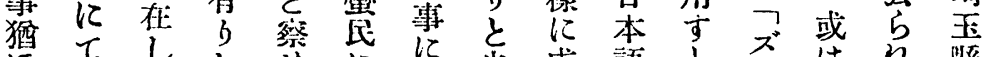

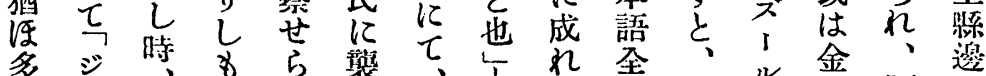

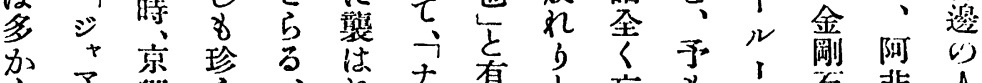

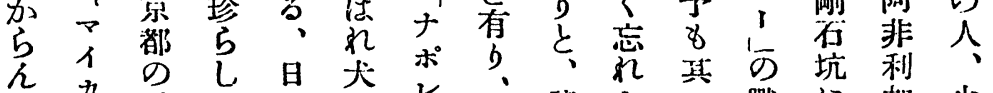

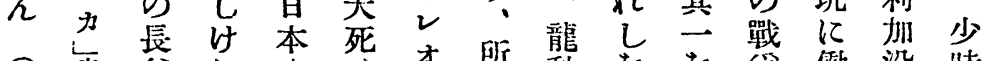

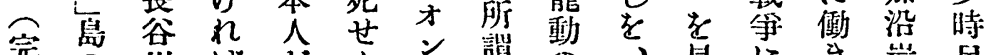

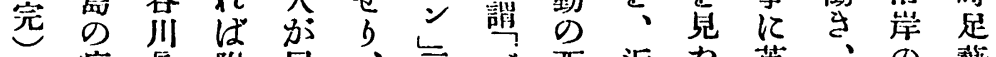
病長附 早、等 ズ西近た英、の掏 